\title{
Contrasting Definitions of High Energy Performance Buildings
}

\author{
Charlotte Verhaeghe ${ }^{1 *}$, Audenaert Amaryllis ${ }^{1}$ and Stijn Verbeke $^{1,2}$ \\ ${ }^{1}$ EMIB, Faculty of Civil Engineering Technology, University of Antwerp, Groenenborgerlaan 171, 2020 Antwerp Belgium \\ ${ }^{2}$ VITO, unit Smart Energy and Built Environment, Belgium, Boeretang 200, 2400 Mol Belgium
}

\begin{abstract}
The rising interest in low energy building has led to an inflation in related terminology: (nearly) zero energy buildings, or (n)ZEBs, passive houses, positive energy buildings and districts, offgrid buildings, energy autarkic buildings, etc. Each of these terms involves (sometimes subtle) differences in interpretations, system boundaries, included energy end uses, etc. This paper maps the differences and overlaps in applications of various cases of residential High Energy Performance Buildings (HEPBs), aiming to contribute in the development of a novel taxonomy to evaluate the extent to which a building can be considered energy or carbon neutral. Three dimensions are suggested for specification in novel taxonomy for HEPBs: (i) the spatial dimension (energy use, locally renewable energy production and sometimes energy storage), (ii) the time dimension (during which period is the building and its systems balanced, e.g. yearly or momentary) and (iii) the end-use dimension (these are the end-uses that are included or excluded for the calculation of the total energy needs of the buildings).
\end{abstract}

\section{Introduction}

International interest in low, zero or beyond zero energy or emission buildings has grown worldwide and therefore, initiatives regarding these buildings are increasing [1]. Several European and non-European public authorities, institutions and non-profit organisations are aiming to accelerate the transition towards a decarbonised building stock [2-5], resulting in a variety of definitions to characterize them. These definitions, are still rather generic and not yet internationally standardized [6]. Many slightly different terms, such as zero net energy buildings, (nearly) zero energy buildings, zero net carbon, zero net energy, autarkic buildings etc., exist. Generally, all buildings aim for zero or beyond zero energy consumption and sometimes even emissions and are referred to in this paper as High Energy Performance Buildings or HEPBs.

Garcia et al. [7] stated that the assessment of HEPBs is ambiguous and that the comparison between these types of buildings across borders is complicated because of the lack of uniformly defined requirements to comply with HEPBs. Without a clear and robust definition for HEPBs and the associated guidelines for the design, operation and evaluation of these buildings very few legitimated examples of HEPBs would exist $[3,4]$. This paper aims to clarify the differences in the interpretation or definitions of HEPBs worldwide. The problems that arise in relation to the compatibility of HEPBs definitions in the world and the consequences for the comparability of these cases are mapped by means of exemplary cases of HEPBs worldwide. Exemplary HEPBs provide relevant information on taxonomy concerns at the international level.
Based on suggestions for Key Performance Indicators (KPIs) in relation to the energy performance of a building or its carbon emissions, problems regarding the cross-country comparison of HEPBs are analysed. Furthermore, recommendations are made on the direction for the development of future HEPB definitions and taxonomic frameworks. This taxonomic framework can then be used to compare HEPBs and share knowledge about best practice solutions, which could benefit stakeholders in the building sector [8].

\section{Key performance indicators HEPBs in literature}

Both the requirements and the application of the HEPBphilosophy are constantly evolving and vary within countries, groups and economies, such as Europe, the US, Australia and the C40 Cities Climate Leadership Group [9-13]. Other attempts to collect exemplary cases for comparison or to obtain information on the effective implementation of the HEPBs requirements at the international level have been undertaken and are reported in literature. In the projects, Key Performance Indicators (KPIs) are used to provide the most relevant information on the HEPBs with regard to the compatibility with national or international requirements and the comparability of the selected cases.

In a report of the Concerted Action (CA) EPBD [14], experience gained by national authorities at European level and in Norway on the effective implementation of the Directive is exchanged. Additionally, the web platform and the national reports provide an overview of HEPB implementations across EU Member States. A collection of European HEPBs

*Corresponding author: Charlotte.verhaeghe@uantwerpen.be 
was made by the International Energy Agency (IEA) [15] as part of the IEA SHC Task 40, Annex 52 project. This project emerges from the lack of a common definition based on scientific research. Marszal et al. [1] defined six core indicators, relevant for the categorisation of HEPBs based on IEA SHC Task 40 and the methodology proposed by Hernandez and Kenny [16]. Based on these core indicators, twelve methodologies are distinguished for the categorisation of HEPBs. In the synthesis report on the national plans for HEPBs, containing the progress of EU member states towards HEPBS, an HEPB-spreadsheet template with key indicators is provided as well [17]. This sheet is used for the collection of exemplary, refurbished buildings. The structure of the table used to collect the key information for the analysis of HEPBs in this report is based on the structure of the GreenBuilding Programme (GBP) database [18]. In 2017, the Asia-Pacific Economic Cooperation (APEC) working group on energy reported the 100 best practice examples of HEPBs [5]. The scope of the project was to collect detailed information on HEPB pilot projects for an indepth comparative study. The outcome of this project was intended to support APEC economies in their promotion of HEPB and to contribute to the related, existing APEC programs. Within the project, a spreadsheet template was developed to collect relevant information on best practice examples of both residential and commercial buildings in the AOEC climates, based on the IEA joint SHC Task 40 database, conducted research at the Nagoya City University, the Chinese MoHURD passive ultra-low energy consumption demonstration investigation template, the United States DOE NREL building database, the ENOB energyoptimized construction database and the Construction 21 database. Similar to the Construction21 database, the ExcEED [8] platform, provides comparable performance data about buildings are gathered worldwide. The aim of this database is to distinguish where to improve the efficiency of existing and future generation buildings regarding control, design and energy performance regulations.

Four mutual KPIs are found in aforementioned projects in relation to cross-country comparison of the energy savings or carbon emission reduction of the HEPBs and are further elaborated in the following paragraphs:

-General information (location, type of building, year of construction and/or year of renovation, conformity with national requirements and certification, cost of the project and financial initiatives)

-The metric (primary energy, final energy or carbon emissions)

- The balance of the metric (period over which the balance is considered, considered end-uses ${ }^{\mathrm{a}}$ )

\footnotetext{
a The end-uses: heating and cooling are in all spreadsheet templates considered. Ventilation, lighting and DHW are in some templates neglected. Electrical appliances and plug loads are in many cases not taken into consideration.
}

-The energy savings (energy efficiency measures, applied RES and their contribution to energy savings)

\section{Noted differences in perception of HEPBs}

29 HEPB examples have been selected from a large set of individual building owners promoting their buildings on the internet, databases and web platforms (Fig. 1). The definitions of HEPBs are used for both residential and non-residential buildings. In this document, however, the focus is on residential construction only, because it represents the largest amount of emissions [19]. Generally speaking, all selected cases aim to reduce fossil energy consumption as much as possible by efforts to save energy and making full use of renewable energy to achieve at least a nearly zero energy level. The selected cases are spread all over the world and have been selected in such a way that they maximally demonstrate the issues regarding comparability of HEPBs worldwide. The aspects of the HEPBs that are elaborated in this paper, are based on the four KPIs that have been identified in previous research and the lessons learned regarding compatibility of the selected cases for this paper.

\subsection{Metric}

As found in the previous paragraph, the metric of the energy balance is usually expressed as primary energy, final energy or carbon emissions. This distinction has also been made by other authors, among which Lausten [20] and Mertz et al. [21]. The metric of the balance has an influence on the distinction between nearly zero, net zero or positive energy buildings on one hand and nearly neutral, neutral or positive footprint buildings on the other hand in this paper. In many of the selected cases, "total energy needs" of a building are used as a metric of the balance, without specifying whether this considers primary or final energy. The exemption is Maison des Yvelines-Nubian Vault in Senegal, in which the focus lies on the reduction of carbon emission. Therefore, the need to make a difference regarding the metric of the balance that has been considered becomes important.

Most of the total energy needs and related delivered energy of the houses is expressed in primary energy $\left[\mathrm{kWh} / \mathrm{p} / \mathrm{m}^{2}\right.$ year]. However, this is not always the case. The energy needs of the Karuna House are for instance, are expressed in $[\mathrm{kWh} /$ year $]$ without mentioning the floor area that is considered, nor whether system losses are included. Furthermore, it is in most cases not clear whether the indicated energy refers to primary energy (sometimes explicitly expressed as $\left[\mathrm{kWh}\right.$ pe $\left./ \mathrm{m}^{2} \mathrm{year}\right]$ ), or secondary energy. For the conversion of the energy needs into primary energy, national conversion factors, 


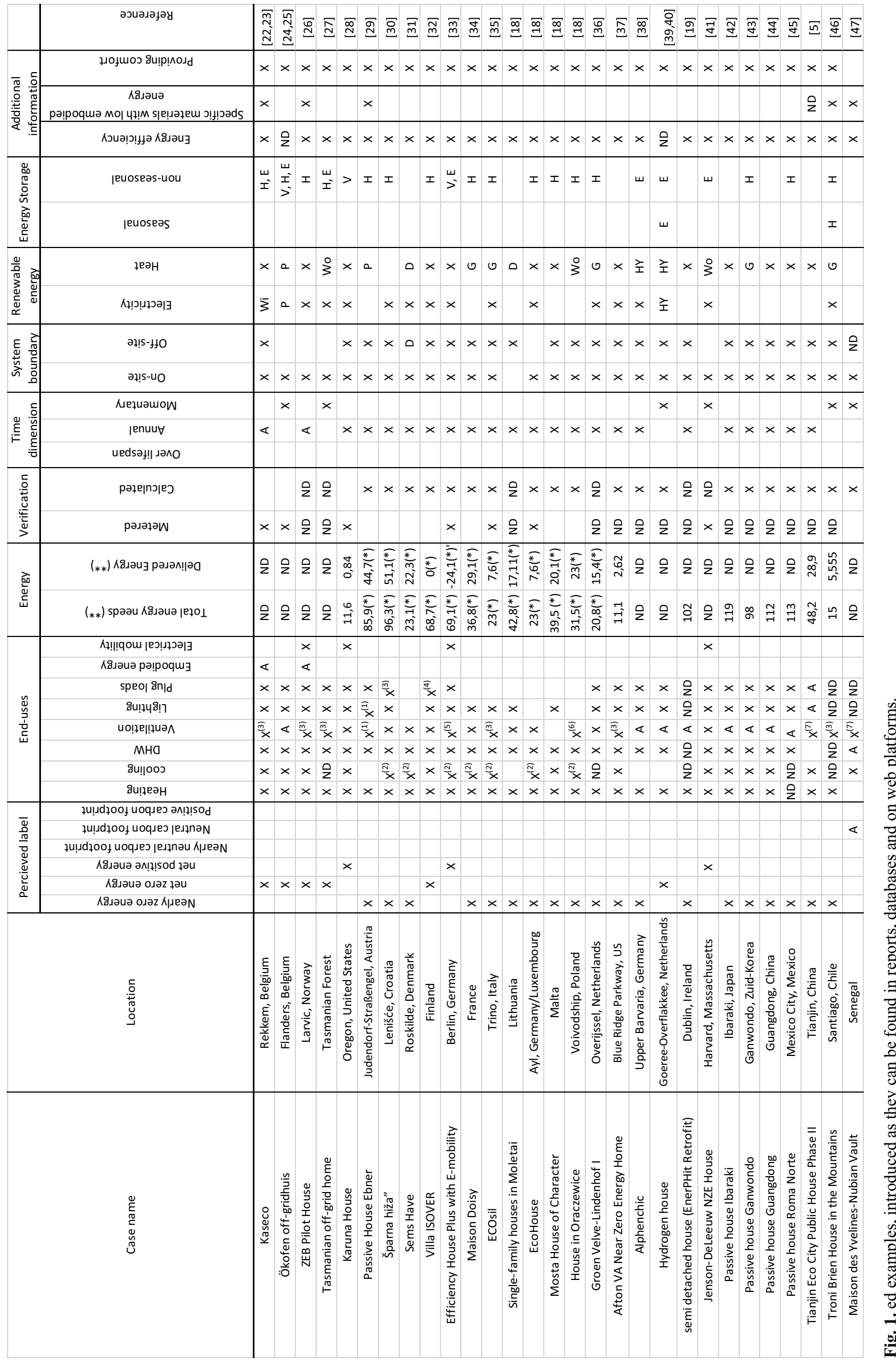


Table 1: Abbreviations

\begin{tabular}{|c|c|}
\hline $\mathrm{G}$ & Condensing gas boiler \\
\hline $\mathrm{Wi}$ & Wind energy \\
\hline HY & Hydrogen \\
\hline Wo & Wood burning stove \\
\hline $\mathrm{P}$ & Pellet boiler \\
\hline $\mathrm{D}$ & District Heating \\
\hline A & Ambiguous \\
\hline ND & Not Documented \\
\hline $\mathrm{H}$ & Heat \\
\hline $\mathrm{E}$ & Electricity \\
\hline $\mathrm{V}$ & Virtual \\
\hline $\mathrm{X}^{(1)}$ & Included in "Plug loads" \\
\hline $\mathrm{X}^{(2)}$ & Cooling loads are $0 \mathrm{kWh} / \mathrm{m}^{2}$ year \\
\hline $\mathrm{X}^{(3)}$ & Not part of the total energy needs \\
\hline $\mathrm{X}^{(4)}$ & Auxiliary energy is included \\
\hline $\mathrm{X}^{(5)}$ & Pumps and automation are included \\
\hline $\mathrm{X}^{(6)}$ & These energy needs are included in "heating" \\
\hline $\mathrm{X}^{(7)}$ & Natural/nocturnal ventilation, $0 \mathrm{kWh} / \mathrm{m}^{2}$ year \\
\hline$(* *)$ & $\begin{array}{l}\text { Expressed in primary energy }\left[\mathrm{kWh}_{\mathrm{ep}} / \mathrm{m}^{2} \mathrm{year}\right] \\
\text { or }\left[\mathrm{kWh} / \mathrm{m}^{2} \mathrm{year}\right] \text { in case ambiguously communicated } \\
\text { or no data for primary energy available. }\end{array}$ \\
\hline$(*)$ & $\begin{array}{l}\text { Energy explicitly expressed as primary energy } \\
{\left[\mathrm{kWh} \mathrm{ep}_{\mathrm{p}} / \mathrm{m}^{2} \mathrm{year}\right]}\end{array}$ \\
\hline
\end{tabular}

or Primary Energy Factors (PEF) are used. These factors are based on a number of pre-defined variables to reflect reality, which may be based on regional or national weighted averages or a specific on-site production value [48], including geographical boundaries for calculation, export and import of energy, efficiency and heat production and the time dimension [49]. Different calculation methods to determine the conversion factor exist, resulting in a varying choice of parameters that influence the size of the conversion factor [50,51]. In many cases, the calculation method for the determination of the conversion factors are not given, although it has an important impact on it. Without knowledge about the calculation method of the conversion factor, or whether the considered energy is primary or final energy and whether system losses are included, the comparison between the cases may lead to erroneous outcomes $[48,51]$. The connection between the energy use and carbon emissions is not reflected by the PEFs [49]. The same applies to supply security and prices. These factors are, however, important aspects of energy policies [48]. The reliability of primary energy consumption for the HEPBs is thereby undermined, which reduces the consistency between the definitions of these buildings. Furthermore, current PEFs may give an advantage to fossil technology, which leads to an encouragement of the use of fossil fuels [49].

Transparency between the HEPB projects is needed, including clarity on the methodologies that are used to assess the buildings energy performance. This is confirmed by $[1,48]$ among others. Garcia et al. [7] suggested to base the determination of the HEPB-level on relative targets, rather than fixed maximum values for primary energy needs or delivered energy, in order to obtain an outcome that is most suitable for cross-country comparison. In this manner, the impact of the local conditions and additional parameters are introduced along with the primary energy needs.

\subsection{Balance of the metric}

The balance of the metric can either be found by summing the various end-uses, or carbon emissions. The total energy needs are, in this article, defined as the sum of the considered end-uses of the building, whereas the reported delivered energy is obtained by the difference between the total energy needs that are provided by nonrenewable energy sources on the one hand, and the total amount of local renewable energy on the other hand, in accordance with the guidelines accompanying the EPBD directive [10]. If the latter is a positive number and close to zero, the building is almost energy neutral, or 'nearly zero energy' and still needs the energy grid (also called hinterland). If this number is zero, the building is energy neutral on annual basis and can therefore be categorized under 'net zero energy building'. A negative number indicates a 'net positive energy' building whose absolute value is the amount of energy put on the grid on an annual basis and is not consumed on-site. The zero energy balance is often ambiguous and inconsistent because of differences in calculation methods and the way boundaries are set [7]. The low carbon emission buildings are referred to as buildings that produce nearly enough, enough or an excess of $\mathrm{CO}_{2}$-free energy to supply themselves with energy on annual basis. If the operation of a building results in a nearly neutral, neutral or beyond neutral balanced carbon footprint at the end of the building lifetime, it contributes to climate protection [28] and is categorized under respectively 'nearly neutral carbon footprint', 'neutral carbon footprint' or 'positive carbon footprint'.

\subsubsection{End-uses}

The exemplary cases show that boundaries for the regulated energy or end-uses to comply with the national definitions for HEPBs, vary across different countries and groups, which has been confirmed by $[2,3]$. The main categories mentioned in literature are heating, cooling, DHW, ventilation, lighting, plug loads and embodied energy $[3,5,52]$.

In many cases, cooling loads, plug loads, embodied energy and electrical mobility are excluded from the end-uses. In general, heating loads, analysed in this paper are accounted for in almost all cases, except for Maison des Yvelines-Nubain Vault in Senegal, where no heating is needed. For the Roma Norte passive house information lacks regarding cooling and heating loads. For Maison Doisy, ECOsil, EcoHouse and the House in Oraczewice, cooling loads are stated to be $0 \mathrm{kWh} / \mathrm{m}^{2}$ year $\left(\mathrm{X}^{(2)}\right)$ by the authors. Though, it was not clear whether this was caused by the absence of cooling devices or absence of data about the cooling loads. Domestic Hot Water (DHW) loads are in most cases considered. Exceptions are the cases in which the end-uses for DHW is ambiguous or not communicated. In some cases 
certain end-uses, as for instance ventilation loads, are included in other end-use categories (e.g. plug loads, or heating loads). Moreover, at a more detailed level, it is not always clear which specific loads belong to each category. When determining the ventilation demand, for example, the associated automation is not always taken into account, which makes it difficult to compare all cases and draw solid conclusions from them. Auxiliary energy loads are often not mentioned. However, this end-use category affects the total energy needs and amount of delivered energy. Moreover, sometimes the energy generated by RES, is already subtracted from the total final end-uses, without mentioning the considered end-uses and the related total energy needs of the building. This is, for example, the case with the public information on the EnerPHit Retrofit in Dublin. Therefore, no conclusions can be drawn regarding the end-use categories and percentage of RES.

In older definitions, the only end-uses that are considered are heating and domestic hot water [19]. Presently, end-uses mainly include HVAC, lighting and domestic hot water [3], which is in accordance with the dataset analysed in this paper. Nearly all EU countries do not include plug loads in building energy calculations since they are not considered permanent in the building [2]. Almost all definitions exclude embodied energy, energy that is required for the manufacturing, maintenance and demolition of the building components [19], which is reflected in the selected cases. One of the reasons for covering operational energy only and excluding embodied energy is the absence of an accurate method to calculate the embodied energy [53]. The article by Liu et al. [3] states that the end-uses usually consider the energy consumption during the operating time of the building. In the Efficiency House Plus with E-mobility, e-mobility is applied for peak shaving, load shifting and reduction of annual energy usage. By introducing this extra end-use category, the energy needs and total delivered energy are affected, while neglecting the advantages regarding the increased energy flexibility. In a summery by Musall et al. [54], based on research under the scope of the IEA SHC Task 40, future options for electric mobility are mentioned as a concept related to on-site generated electricity. The combined integration of RES and plug-in electrical vehicles (PEVs) in microgrids is becoming increasingly popular [55], hence their relevance in the end-use categories.

In some cases, embodied energy is considered in the calculation of the end-uses of HEPBs in other cases, this is neglected. The irregularity regarding the inclusion or non-inclusion of embodied energy in the assessment of HEPBs is recognized, e.g. in [10]. Panagiotis et al. [56] states that the share of embodied energy, or grey energy, for HEPB is becoming more important and in some cases already amounts to $74 \%$ to $100 \%$ of the total energy. Energy efficiency legislation often takes into account the effect of the operational phase of the building, while ignoring the impact of embodied energy on the balance of the metric during the life cycle of the building. It is concluded that the total energy needs and amount of delivered energy of the buildings are not comparable if the end-uses that are considered are different. To overcome this, it is advised to quantify each category of end-uses. This way, the sum of the matching categories can be compared.

Metering the energy data of a building allows for an efficient collection of information regarding the building energy needs (peaks, medians, extreme values or outliers and seasonal variations) [57]. Building energy models can be used to predict the energy needs and therefore also delivered energy of a building without the need for experimentation. However, the accuracy of the predicted energy use, the HVAC, renewable energy systems and the occupant's behaviour needs to be improved in many cases [58]. These models can be calibrated to increase the accuracy by means of the widespread environmental and energy monitoring equipment [57]. In many cases, it is not stated whether the total energy needs and related delivered energy are based on either measured or calculated data. In order to give an idea about the accuracy of the energy data, a distinction is made between metered and calculated energy data.

Some buildings are designed as net zero energy buildings. However, in reality, they may not achieve the net zero energy level every year [59]. Therefore, the category to which a building belongs, if solely based on metered energy data, depends on the given year, which itself depends on weather conditions, conditions of the building, user behaviour, etc. This is a disadvantage of metered energy data. In many cases, the energy needs are based on measurements only, conducted in a certain year. This limits the conclusions that can be drawn from them. By simulating the energy needs of the building, based on an exemplary year, this issue can be overcome.

\subsubsection{Time dimension}

A building can generate enough and sometimes even more renewable energy during its lifetime to cover the total energy needs. Other building owners aim at an energy or carbon neutral level at any time, month or year. This scope may, however, not be clear without specifying the time during which the metric is balanced. Therefore, the time dimension is defined, distinguishing between a momentary, monthly, annual or lifespan balance. Based on the selected examples, it is concluded that many HEPBs consider annual generated energy, while only a few take time dependency into account. In the US State of California for instance, time dependency is evaluated as a significant factor. This way, benefits of on-site renewable energy production during peak demand hours in a neighbourhood or distribution network become more important. The disadvantages of the intermittent energy production of, for instance, PVpanels [60], are therefore considered as well.

\subsection{Energy savings}

\subsubsection{Energy efficiency measures}

According to Panagiotidou et al. [19], the core of the definition of HEPBs is a minimalization of the building energy consumption by means of energy efficiency 
measures. Passive approaches are usually the first steps in a HEPB design. Some projects, such as Maison des Yvelines-Nubian Vault, can already reach the net zero or nearly zero energy level without needing to apply RES and a control system, which has also been described for other cases in projects, such as [5]. In case the passive approaches are insufficient to reach this HEPB level, the residual energy is to a large extend or completely met by RES. The order in which efficiency measures are applied has an influence on the cost-effectiveness of these measures. Energy efficiency measures for renovation are for instance often less expensive measures initially. However, at a certain point, carbon emission reduction measures become more economical to add than a further improvement of the energy efficiency measures. By combining the energy efficiency measures with the use of renewable energy, the depth of the renovation works that are needed can be reduced [61].

Information regarding the energy efficiency measures that have been applied, sometimes lacks. In the Ökofen building and the hydrogen house, for instance, no information is provided regarding the energy efficiency measures on the building envelope. The net zero energy level is therefore possibly obtained by providing local renewable energy production and energy storage solely, without improving the energy efficiency of the building envelope in the first place. For other buildings, the embodied energy is not calculated as part of the total energy needs of the building, despite the fact that attention is paid to the embodied energy for the selection of construction materials. Readers may mistakenly think no effort has been made regarding the reduction of embodied energy in buildings. Furthermore, a reduction in the energy requirements for the operation of the building is strongly linked to the control systems and the performance of integrated active and passive building systems [62]. It is therefore suggested to specify whether energy efficiency measures are applied and if attention is paid to the embodied energy of the construction materials and systems.

\subsubsection{RES}

The main concept of the HEPB is its independence of fossil fuels. As a consequence, dependence on renewable energy production by RES increases[63]. Not all local renewable energy and storage solutions are accounted for in the calculations of the energy consumption in every economic unit or country $[2,7,64]$, while they are sometimes applied on exemplary cases. Information regarding the RES of the collected HEPBs was gathered in the matrix. A distinction is made between heat and/or electricity production.

In most cases, PV panels, and/or solar collectors and/or a heat pump are applied, similar to previous research e.g. [52,65]. In some buildings, a wood burning stove (Wo) is provided for extreme conditions when other RES are not sufficient. A wood-burning stove can be considered as a low-carbon technology when fuelled by local residual biomass to meet remaining heat demands during the coldest periods [66]. In other cases, a condensing pellet boiler is installed. In both scenarios, biomass is used as local RES. The $\mathrm{CO}_{2}$ that is being captured in the biomass is returned to the atmosphere through combustion, resulting in a net zero increase in $\mathrm{CO}_{2}$. However, the life cycle analysis in respect to the $\mathrm{CO}_{2}$-emissions is what defines the actual carbon footprint of the biomass as a combustible and depends largely on the physical boundaries of the considered case. It was for instance not always specified whether the biomass is renewed. The origin of the biomass may be on-site or off-site. In case it is off-site, the transportation radius becomes important, having an impact on the primary energy that is related to the energy source. In case the harvest, transport, production process and delivery to the house of the biomass is taken into account, this process cannot always be seen as carbon neutral anymore [67]. The combustion technology and automation for the renewable energy production by means of biomass also have an important impact on the energetic efficiency of the renewable energy production $[66,68]$. By specifying these techniques in more detail, more robust conclusions can be drawn regarding the HEPB-level of the building relative to other HEPBs. The same applies to all other RES, such as PV-panels, solar collectors, heat pumps etc.

According to Torcellini et al. [60], an indication of the supply side of RES is needed, for which two options exist: either on-site or off-site supply [63]. According to Lausten [20], a building that is off-grid, does not require a connection to the grid in general, only as backup. These buildings are self-sufficient as they have the capacity to produce energy and store energy for nighttime or winter use. On-site refers to energy production in and on the building and the plot belonging to the building, all others are considered as off-site, including district heating. Controversy exists about the physical boundaries for the definition of on-site and off-site energy production. In only one out of 30 cases, wind is harnessed. If the windmill is located in the garden, men can argue about whether this can still be considered as on-site or should this be categorized as off-site. In many other cases the RES are complemented by means of offsite energy. In some cases, a condensing gas boiler $(\mathrm{G})$ is used as a system for the provision of additional heat. In Maison Doisy, it is for instance complemented with a heat pump. Another example is EcoSil, in which the solar thermal collector and a heat recovery system are complemented with a gas boiler. The extraction of natural gas for the supply of the gas boiler is not renewable. In other cases, district heating (DH) is seen as a source of renewable energy. The grid that supplies the additional energy, or hinterland, not only refers to the electricity grid, but also to heat and cold carriers (such as a district heating networks) plus any other energy carrier (such as biomass, biogas, syngas) [69]. The hinterland can either supply non-renewable energy, renewable energy or energy that would normally go to waste. In this perspective, the physical boundaries of the system become important. The HEPB and the source of the district heating can for instance be considered within a Positive Energy District (PEDs) [69,70], and therefore considering the district heating as on-site energy 
production. Controversy exists about extent to which the latter is renewable. One should ask themselves whether the district heating can be considered to be renewable energy production. In conclusion, physical or system boundaries are once more suggested as an important parameter for the definition of HEPBs and a more complete set of generally acceptable renewable energy production sources may need to be specified.

\subsubsection{Energy storage}

In $77 \%$ of the selected cases, non-seasonal energy storage is provided, whereas seasonal energy storage is applied in $7 \%$ of the selected cases. Many buildings use the energy grid to cover for energy surpluses and shortcomings, resulting in peak shaving, load shifting and reduction of annual energy usage, increasing the energy flexibility of the building stock. The efficiency of the storage techniques has an impact on the selfsufficiency level of the buildings and therefore, may need specification. In both Alphenchic and Hydrogen House hydrogen fuel cells are used to store energy. The difference between both is the efficiency of the system. In Alphenchic, hydrogen is used to produce solely electricity, losing waste heat, whereas heat has been harnessed in the Hydrogen House [39]. This difference stresses the additional need for a distinction between heat and electricity storage. Some HEPBs make use of virtual energy storage (V). The latter refers to the application of an energy storage management systems to increase the efficiency of the single storage devices [71]. Generally it is concluded that energy storage has an influence on the general efficiency of the complete energy system in a building, therefore also total energy needs of a building and the level of self-sufficiency of the building. Furthermore, mapping energy storage, leads to an increased knowledge on the progress regarding energy flexibility of the building stock.

\subsubsection{Co-benefits}

Previous studies argue that many other benefits exist besides the energy benefits, also referred to as the cobenefits or non-energetic benefits (NEBs), related to energy efficiency measures. These benefits lead to the overall quality of the building, the users well-being and economic benefits [72]. In HEPBs, for which energy efficiency measures are provided, and therefore tend to be well-insulated and airtight, the indoor climate becomes more important and therefore, the control of the comfort should be more stressed [13]. Furthermore, by leaving out heating and cooling installations, nor installations for DHW in the building design, the total energy needs of the building decreases, yet comfort decreases as well, which results in a distinction between for instance Maison des Yvelines-Nubian Vault and the other cases.

\subsection{Additional information}

Garcia et al. [7,65] stated that the climate conditions are one of the main parameters that have an influence on the cross-country comparison on HEPBs. This parameter came also forward in the above mentioned projects. Therefore, a column that describes the location of the buildings is introduced to provide insights on how the real exemplary project may or may not vary from the country specific regulations in future research.

The large investments that are needed for the HEPBs is still a big obstacle for the commercialization of these buildings. Therefore, the application of HEPBs depends heavily on economics and prices in a country [5]. In some projects, information is provided regarding investment costs and subsidies [17,37,73,74], however, this is not the case for all projects.

\subsection{Conclusions}

By gathering the various international case-studies, it can be concluded that the application of the definitions of (n)ZEBs in practice is inconsistent. The template that has been developed for the categorisation of selected examples of HEPBs is very detailed. Some projects do not provide all information that is required for the template. This is consistently indicated in the template as "ND" or not documented. In some cases, the information may be ambiguous, only providing limited and incomplete information. Most exemplary cases can be found in Canada, the U.S, Europe, Asia, Australia and New-Zeeland, lacking exemplary buildings in other continents. An increased amount of exemplary cases leads to a more elaborated matrix and the distinction of new subcategories, introducing more detail to the various categories.

\section{Conclusions and recommendations}

Definitions and requirements for HEPBs are still very generic and not yet standardized across the world, resulting in difficulties in comparing these type of buildings between nations, groups and economies. Without establishing a robust framework for the definition of HEPBs, the uncertainties in design, operation and evaluation of these buildings will remain problematic for the comparability between HEPBs. By selecting exemplary cases, insights regarding the definition and comparability between cases can be obtained. Based on literature, core indicators are extracted for the collection of selected examples of HEPBs. The resulting developed spreadsheet template consists of KPIs, describing the location, perceived label, various end-uses that are taken into account, annual energy needs, way in which the annual energy is verified, time dimension, system boundaries, renewable energy, energy storage, whether efficiency measures are taken, whether attention is paid regarding the embodied energy and if the building provides comfort. Based on the experience that is retrieved by collecting exemplary HEPBs, it is concluded that the issues regarding the compatibility between HEPBs are mainly located in three dimensions: 
-Spatial dimension or system boundaries for: (i) end-use (ii) locally renewable energy production (heat and or electricity) (iii) sometimes energy storage (seasonal or nonseasonable) (iii) system efficiency measures

- Time dimension: during which period is the building and its systems balanced, e.g. over the lifespan of the building, yearly, monthly or momentary.

-End-use dimension or regulated energy: the selection of the end-uses that are included or excluded for the calculation of the total energy needs of the buildings (heating, cooling, DHW, ventilation, lighting, plug loads, embodied energy and electrical mobility, related annual energy needs and how this is verified)

It is suggested that, when developing a taxonomy, special attention is paid to these dimensions. Based on the dimensions, a set of consistent HEPB-related terms can be set up by means of a robust framework. A database for international HEPBs, based on a worldwide harmonized framework with open access, can encourage a correct implementation of the building requirements per category. Examples of such databases can be found in $[8,44,47]$. Recognitions and awards can either adjust to the used terminology to comply with the above mentioned set of terms for HEPB-related buildings, or an overview can be made of the awards and recognitions around the world within the a common framework for definitions worldwide. As stated by [2], the requirements and applications of HEPB-philosophy is under constant evolution. Finally, this cross-country database would also allow to represent a HEPB learning curve, the relative penetration of the building stock and the development of information during the design process for relevant stakeholders (architects, project developers, building owners and manufacturers).

\section{References}

1. A.J. Marszal, P. Heiselberg, J.S. Bourrelle, E. Musall, K. Voss, I. Sartori, A. Napolitano, Zero Energy Building - A review of definitions and calculation methodologies, Energy Build. 43, 971-979, (2011).

2. Build Up, Overview | Zero-Energy Buildings: does the definition influence their design and implementation?, (2019), Available online: https://www.buildup.eu/en/news/overview-zeroenergy-buildings-does-definition-influence-theirdesign-and-implementation.

3. Z. Liu, Q. Zhou, Z. Tian, B. He, G. Jin, $A$ comprehensive analysis on definitions, development, and policies of nearly zero energy buildings in China, Renew. Sustain. Energy Rev. 114, 109314, (2019).

4. P. Singh, R. Verma, Zero-Energy Buildings- $A$ Review, S-JPSET 5, 2229-7111, (2007).

5. X. Wei, Z. Shicong, APEC 100 Best Practice Analysis of Nearly / Net Zero Energy Building;
(2017);

6. I. Sartori, A. Napolitano, K. Voss, Net zero energy buildings: A consistent definition

framework, Energy Build. 48, 220-232, (2012).

7. J.F. Garcia, L. Kranzl, Ambition levels of nearly zero energy buildings ( $n Z E B$ ) definitions: $A n$ approach for cross-country comparison, Buildings 8, (2018).

8. ExcEED, (2020), Available online: http://www.exceedproject.eu/exceed-knowledgesharing/data-from-the-exceed-platformintelligence-for-better-buildings/ (accessed on Jan 24, 2020).

9. European Union, Directive 2010/31/EU Of the European Parliament and of the Council of 19 May 2010 on the energy performance of buildings (recast), EUR-Lex 13-35, (2010).

10. European Commission, Comission Delegated Regulation (EU) No 244/2012: supplementing Directive 2010/31/EU of the European Parliament and of the Council on the energy performance of buildings by establishing a comparative methodology framework for calculating cost-optimal level (2012), No 244/201, L81/18-L81/36.

11. U.States President, Federal Leadership in environmental, energy, and economic performance, Environ. Policy Collect. 74, 52117-52127, (2009).

12. N.I. C. Riedy, A. Lederwasch, Defining Zero Emission Buildings - Review and Recommendations: Final Report, Aust. Sustain. Built Environ. Counc. (2011).

13. J. Kurnitski (Ed.), Cost optimal and nearly zeroenergy buildings (nZEB): definitions, calculation principles and case studies, (2013), Available online:

www.springer.com/us/book/9781447156093 (accessed on Jan 12, 2020).

14. CA EPBD, About us, (2019), Available online: https://epbd-ca.eu/about-us.

15. IEA SHC, IEA SHC \| Task 40: Net Zero Energy Solar Buildings, (2017), Available online: http://task40.iea-shc.org/ (accessed on Jan 8, 2020).

16. P. Hernandez, P. Kenny, From net energy to zero energy buildings: Defining life cycle zero energy buildings (LC-ZEB), Energy Build. 42, 815-821, (2010).

17. H. Erhorn, H. Erhorn-Kluttig, Selected examples of Nearly Zero- Energy Buildings; (2014);

18. D. D'Agostino, P. Zangheri, B. Cuniberti, D. Paci, P. Bertoldi, Synthesis Report on the National Plans for Nearly Zero Energy Buildings ( NZEBs ); (2016);

19. M. Panagiotidou, R.J. Fuller, Progress in ZEBs$A$ review of definitions, policies and construction activity, Energy Policy 62, 196-206, (2013).

20. J. Laustsen, Energy efficiency requirements in building codes, energy efficiency policies for new buildings, IEA Inf. Pap. 1-85, (2008).

21. G.A. Mertz, G.S. Raffio, K. Kissock, Cost 
optimization of net-zero energy house. In Proceedings of the Energy Sustainability Conference 2007; (2007); pp. 477-488.

22. L. Verhulst, Kaseco: de eerste autonome bioecologische kaswoning in België, (2018), Available online: https://architectura.be/nl/nieuws/23731/kasecode-eerste-autonome-bio-ecologische-kaswoningin-belgie (accessed on Jan 8, 2020).

23. Kaseco, De eerste autonome bio-ecologische kaswoning in België, (2020), Available online: https://www.kaseco.plus/nl/autonome-bioecologische-kaswoning (accessed on Jan 8, 2020).

24. Ökofen, ÖkoFEN Belgium stelt eerste offgridhuis in België voor, (2018), Available online: https:/www.oekofen.com/nl-be/nieuws/oekofenbelgium-stelt-eerste-offgrid-huis-in-belgie-voor$-16711 /$ (accessed on Jan 8, 2020).

25. Victron energy, ÖkoFEN Off-grid, (2020), Available online: www.offgridhuis.be (accessed on Jan 8,2020 ).

26. Snøhetta, ZEB Pilot House, (2020), Available online: https://snohetta.com/project/188-zebpilot-house (accessed on Jan 8, 2020).

27. E. Giblin, Tasmanian off-grid home inspires sustainable living, (2018), Available online: https://www.realestate.com.au/lifestyle/tasmania n-off-grid-home-inspires-sustainable-living/.

28. Whole Building Design Guide, Karuna House, (2016), Available online:

https:/www.wbdg.org/additional-resources/casestudies/karuna-house (accessed on Jan 8, 2020).

29. SustainCo, STRAW - House Ebner Case study, (2014), Available online:

https://docplayer.net/47512839-Straw-houseebner-case-study.html (accessed on Jan 8, 2020).

30. APOS, Šparna hiža”, (2020), Available online: https://apos-koprivnica.hr/ (accessed on Jan 8, 2020).

31. Renover, Sems Have, (2020), Available online: https://renover.dk/projekt/sems-have/ (accessed on Jan 8,2020 ).

32. The Multi Comfort Hub, Villa Isover, (2020), Available online: https://multicomfort.saintgobain.com/project-gallery/hyvinkaa-finland (accessed on Jan 8, 2020).

33. BuildUp, Efficiency House Plus in Berlin, (2014), Available online:

https://www.buildup.eu/en/practices/cases/efficie ncy-house-plus-berlin (accessed on Jan 8, 2020).

34. Observatoire BBC, Maison Doisy, (2020), Available online:

https://www.observatoirebbc.org/construction/13 39 (accessed on Jan 8, 2020).

35. C. Becchio, G.C. La Loggia, L. Orlietti, Certified ClimateHouse building in Mediterranean climate, Rehva (2014).

36. RVO, Podium duurzame gebouwen, (2019), Available online: https://ez.maps.arcgis.com/apps/MapSeries/inde x.html?appid=6b991a9506804f138139b4938163 b1d3 (accessed on Jan 8, 2020).

37. Northeast Ssustainable Energy Association, Afton VA Near Zero Energy Home, (2020), Available online: http://nesea.org/project-casestudy/afton-va-near-zero-energy-home/general (accessed on Jan 8, 2020).

38. Baufritz, Show house Alpenchic, (2016), Available online:

https://www.baufritz.com/uk/energy-andsafety/energy-self-sufficient-house/show-housealpenchic/\#site (accessed on Jan 8, 2020).

39. Solencopower, Solenco Powerbox: The missing link for mass uptake of residential Solar PV, (2018), Available online:

http://www.solencopower.com/frontpage/capital-firm/ (accessed on Jan 8, 2020).

40. Luc Pauwels, Wim De Maeseneer, Nederland stelt eerste waterstofwoning voor, (2019), Available online:

https://www.vrt.be/vrtnws/nl/2019/09/11/nederla nd-stelt-eerste-waterstofwoning-voor/ (accessed on Jan 8, 2020).

41. P. Pintos, Jenson-DeLeeuw NZE House, (2019), Available online:

https://www.archdaily.com/924727/jenson-

deleeuw-nze-house-paul-lukez-

architecture?ad_source $=$ search\&ad_medium $=$ sea rch_result_projects (accessed on Jan 8, 2020).

42. International Passive House Association, Passive house Ibaraki Japan, (2020), Available online: https://passivehouse-database.org/\#d_2050 (accessed on Jan 8, 2020).

43. International Passive House Association, Passive house Ganwondo, Available online: https://passivehouse-database.org/\#d 4017\%0A (accessed on Jan 8, 2020).

44. International Passive House Association, Passive house Guangdong, Available online: https://passivehouse-database.org/\#d 4243\%0A (accessed on Jan 8, 2020).

45. International Passive House Association, Passive House Roma Norte, Available online: https://passivehouse-database.org/\#d_2959 (accessed on Jan 8, 2020).

46. Clément Guillard, Troni Brien House in the mountains, (2015), Available online: https://www.construction21.org/casestudies/h/troni-house.html (accessed on Jan 14, 2020).

47. C21 France la Redaction, Maison des Yvelines Nubian Vault, (2016), Available online: https://www.construction21.org/casestudies/h/maison-des-yvelines-nubian-vault.html (accessed on Jan 14, 2020).

48. R. Hitchin, K. Engelund Tomsen, K.B. Wittchen, Primary Energy Factors and Members States Energy Regulations; (2018);

49. AIE, DEA, Dong energy, EHPA, ECI, Schneider Electric, EnergiNorge, Statkraft, Verbund, Euha, et al., The importance of a revised Primary Energy Factor (PEF): Towards achieving the EU's long term energy \& climate targets; 
(2017);

50. A. Esser, F. Sensfuss, Evaluation of primary energy factor calculation options for electricity; (2016);

51. ADAPT consulting as, Conversion Factors for Electricity in Energy Policy; (2013);

52. H. Erhorn, H. Erhorn-Kluttig, Selected examples of Nearly ZeroEnergy Buildings, 74, (2014).

53. R.S. Srinivasan, W.W. Braham, D.E. Campbell, C.D. Curcija, Re(De)fining Net Zero Energy: Renewable Emergy Balance in environmental building design, Build. Environ. 47, 300-315, (2012).

54. E. Musall, T. Weiss, K. Voss, A. Lenoir, Net Zero Energy Solar Buildings : An Overview and Analysis on Worldwide Building Projects, EuroSun 1-9, (2006).

55. M. Hossain, K. Tushar, C. Assi, S. Member, M. Maier, S. Member, Smart Microgrids : Optimal Joint Scheduling for Electric Vehicles and Home Appliances, IEEE Trans. Smart Grid 5, 239-250, (2014).

56. P. Chastas, T. Theodosiou, K.J. Kontoleon, D. Bikas, The effect of embodied impact on the costoptimal levels of nearly zero energy buildings: A case study of a residential building in Thessaloniki, Greece, Energies 10, (2017).

57. M. Royapoor, T. Roskilly, Building model calibration using energy and environmental data, Energy Build. 94, 109-120, (2015).

58. E.M. Ryan, T.F. Sanquist, Validation of building energy modeling tools under idealized and realistic conditions, Energy Build. 47, 375-382, (2012).

59. P.A.T. D. Crawley, S.D. Pless, Getting to Net Zero Energy Buildings, ASHRAE J. 51, 18-25, (2009).

60. P. Torcellini, S. Pless, M. Deru, D. Crawley, Zero Energy Buildings: A Critical Look at the Definition. In Proceedings of the ACEEE Summer Study Pacific Grove; (2006); p. 15.

61. M. Almeida, M. Ferreira, Cost effective energy and carbon emissions optimization in building renovation (Annex 56), Energy Build. 152718 738, (2017).

62. A.L. Pisello, M. Bobker, F. Cotana, A building energy efficiency optimization method by evaluating the effective thermal zones occupancy, Energies 5, 5257-5278, (2012).

63. A.J. Marszal, P. Heiselberg, A literature review of Zero Energy Building (ZEB) definitions; Aalborg University, Denmark, (2009);

64. CA EPBD, (CT1) New buildings \& NZEBs, (2018), Available online: https://epbd-ca.eu/caoutcomes/outcomes-2015-2018/book2018/ct/new-buildings-nzebs.

65. G. Paoletti, R.P. Pascuas, R. Pernetti, R. Lollini, Nearly Zero Energy Buildings: An overview of the main construction features across Europe, Buildings 7, (2017).

66. R.L. Carvalho, O.M. Jensen, A. Afshari, N.C. Bergsøe, Wood-burning stoves in low-carbon dwellings, Energy Build. 59, 244-251, (2013).

67. L. Dion, D. Molesworth, G. Proulx-gobeil, $A n$ Alternative Energy Source for The Raymond Greenhouse: Wood Pellets; (2008);

68. G. Di Giacomo, L. Taglieri, Renewable energy benefits with conversion of woody residues to pellets, Energy 34, 724-731, (2009).

69. C.W. Package, D9. 3 : Report on Attendance at Events Held By Other SCCO1 Coordinators, 115, (2019).

70. Urban Europe, Positive Energy Districts (PED), (2019), Available online: https://jpiurbaneurope.eu/ped/ (accessed on Jan 23, 2020).

71. D. Unger, J.M.A. Myrzik, Agent based management of energy storage devices within a Virtual Energy Storage. In Proceedings of the Energytech IEEE 2013,; IEEE, (2013); pp. 1-6.

72. IEA, Annex 56: Cost-effective energy and carbon emission optimization in building renovation, (2017), Available online: http://www.ieaannex56.org/index.aspx?MenuID=1.

73. Northeast Sustainable Energy Association, Torcellini Residence, Available online: http://nesea.org/project-case-study/torcelliniresidence/energy (accessed on Jan 8, 2020).

74. Northeast Ssustainable Energy Association, Charlotte VT House, (2020), Available online: http://nesea.org/project-case-study/charlotte-vthouse/energy (accessed on Jan 8, 2020). 